\title{
Cosmetic Earnings Management before and after Corporate Governance Legislation in Canada
}

\author{
Charles E. Jordan ${ }^{1}$, Stanley J. Clark ${ }^{2}$ \& Marilyn A. Waldron ${ }^{3}$ \\ ${ }^{1}$ Department of Accounting, Florida State University-Panama City, Panama City, Florida, USA \\ ${ }^{2}$ Department of Accounting, Middle Tennessee State University, Murfreesboro, Tennessee, USA \\ ${ }^{3}$ Business Programs Unit, University of Sydney, Sydney, New South Wales, Australia \\ Correspondence: Charles E. Jordan, Florida State University-Panama City, 8339 High Point Rd., Panama City, FL, \\ 32404, USA. Tel: 1-850-872-0085. E-mail: cejordan@fsu.edu
}

Received: October 10, 2014

Accepted: October 27, 2014

Online Published: October 29, 2014

doi:10.5430/afr.v3n4p105

URL: http://dx.doi.org/10.5430/afr.v3n4p105

\begin{abstract}
Cosmetic earnings management (CEM) occurs when income is rounded (manipulated) up by a relatively small increment to reach a key reference point for users, which creates a disproportionately more favorable view of the company than would have existed otherwise. Significant research shows this type of biased reporting occurred virtually worldwide prior to the corporate governance legislation enacted in many countries in the early-to-mid 2000s. However, more recent research provides evidence that CEM in the U.S. disappeared after implementation of the Sarbanes-Oxley Act (SOX) of 2002. Yet, outside the U.S., little research exists on this form of earnings management following the enactment of similar corporate governance legislation. Using Benford's Law and digital analysis, the current study tests for CEM in Canada before and after Ontario Bill 198 and other corporate governance legislation in that country. The results reveal clear signs of CEM in Canada prior to this legislation but no indications of it afterward, thus suggesting the legislation contributed to the eradication of CEM in Canada much like SOX did in the U.S.
\end{abstract}

Keywords: Cosmetic earnings management, Canada, Corporate governance legislation, Benford's Law

\section{Introduction}

Jackson and Pitman (2001) note that earnings management represents biased financial reporting with the goal of creating personal gain. Healy and Wahlen $(1999$, p. 368) provide an expanded definition indicating that earnings management occurs "when managers use judgment in financial reporting and in structuring transactions to alter financial reports to either mislead some stakeholders ... or to influence contractual outcomes that depend on reported accounting numbers." Judgments and estimates are an integral part of financial reporting and have benign effects on this process so long as they are made in a neutral manner. A problem occurs, though, when these judgments and estimates are made by management to produce desired outcomes.

In the late 1990s, the chairman of the Securities and Exchange Commission (SEC) in the U.S. (i.e., Arthur Levitt) proclaimed the incidence of earnings management in that country had become so rampant that it threatened the credibility of the financial reporting process (Ketz, 1999). Within just a few years of this proclamation, major accounting scandals in the U.S. (e.g., Enron, WorldCom, HealthSouth, Tyco, etc.) proved Levitt to be correct. During that period, public confidence in U.S. financial accounting plummeted to depths not seen since the stock market crash of 1929.

Reacting quickly to these financial reporting scandals, U.S. legislators enacted the Sarbanes-Oxley Act (SOX) of 2002, which made it clear that fraudulent reporting would be met with harsh fines and possible imprisonment for top management involved. The idea was to re-instill integrity in the preparation of financial statements and bolster investor confidence in this reporting process. Recent research suggests SOX, indeed, provided a positive effect on financial reporting in the U.S. as accrual-based earnings management declined noticeably subsequent to this legislation (e.g., Bartov \& Cohen, 2009; Cohen, Dey, \& Lys, 2008; Ibrahim, Xu, \& Rogers, 2011; Kalelkar \& Nwaeze, 2011). 
The present study examines one specific type of earnings management often referred to as cosmetic earnings management (CEM). CEM exists when unmanipulated income falls just under a cognitive reference point for users and management increases earnings by the small amount needed to reach that point (e.g., income of $\$ 4.96$ billion would be enhanced to $\$ 5.00$ billion). The purpose of this manipulation is to boost the left-most (i.e., first) earnings digit by one, as this digit is viewed by users as the most important digit and frequently may be the only one remembered by them (Carslaw, 1988). A significant stream of research shows CEM existed in the U.S. and many other countries throughout the 1980s and 1990s (e.g., Kinnunen \& Koskela, 2003; Niskanen \& Keloharju, 2000; Thomas, 1989; Van Caneghem, 2002).

Following the implementation of SOX in 2002, several studies (e.g., Aono \& Guan, 2008; Jordan \& Clark, 2011; Lin $\& \mathrm{Wu}, 2014)$ tested for CEM in the U.S. and found evidence indicating that it had largely vanished, thus leading to the conclusion that SOX was a major factor in its demise. Numerous countries other than the U.S. passed SOX-like corporate governance legislation in the early-to-mid 2000s as well. Yet, outside the U.S., there exists a paucity of research on the effects of this legislation on the practice of CEM. The current study fills a void in the literature by testing for CEM in Canada before and after the SOX-like legislation in that country (often referred to as CSOX). The results show that in the pre-CSOX period, clear evidence of CEM exists while no signs of it appear in the post-CSOX era. This finding suggests that CSOX contributed to the elimination of this form of biased financial reporting in Canada.

In section two, we examine the literature related to CEM and develop the research hypotheses for the study. Then, we address the methodology and data selection in section three, which is followed by the results in section four and finally our discussion and conclusion in section five.

\section{CEM Literature Review}

Carslaw (1988) laid the groundwork for all CEM studies to follow. He based his theory in part on the $\$ 1.99$ pricing phenomenon in marketing, whereby a consumer views a price of $\$ 1.99$ to be significantly lower than a price of $\$ 2.00$. Furthermore, he noted that people have a finite (i.e., limited) amount of memory and tend to round down and remember only the more important digits within a number, with the left-most digits being the most important. Thus, in remembering a number like $\$ 398$, Carslaw (1988, p. 322) notes that people would normally "round down to $\$ 390$ or $\$ 300$ rather than up to the more rational reference point of $\$ 400$." This is why retailers set selling prices just below user reference points (i.e., because consumers in their recollection of numbers round down, rather than up). Carslaw (1988) extended this concept to accounting earnings and speculated that key reference numbers would be viewed by users as benchmarks. He also hypothesized that if unmanipulated earnings falls just under a reference point (e.g., \$296 million), management would boost income through real or artificial means just enough to increase the first digit by one (e.g., to slightly above $\$ 300$ million).

Carslaw (1988) assumed that if this manipulation occurs in practice, for a large sample of firms there should exist in the second-from-the-left position of the income number an abnormally low rate of large digits (e.g., eights and nines) accompanied by a significantly higher than anticipated frequency of small digits (e.g., zeroes and ones). He tested his theory on 220 listed New Zealand firms with positive income for the period 1981-1985 and found exactly what he had hypothesized. For ordinary income, nines appeared in the second digital position significantly less often than anticipated while zeroes occurred at an abnormally high rate. All other numbers (i.e., one through eight) appeared in the second position at their expected rates.

Thomas (1989) replicated and expanded Carslaw's (1988) work, but did so in regard to U.S. financial reporting. Testing for CEM among U.S. listed companies in 1986 that reported positive income, he found results similar to Carslaw (1988). More specifically, eights and nines occurred significantly less often than anticipated in the second numeric position of earnings, while zeroes appeared at an abnormally high rate. All other digits occurred in the second position at their expected rates. Unlike Carslaw (1988), Thomas (1989) also examined companies reporting losses and discovered the opposite behavior. That is, negative earnings firms reported a significantly greater than expected frequency of nines in the second digit accompanied by an abnormally low rate of zeroes. This suggested that companies reporting losses tended to avoid presenting round numbers and instead preferred to report losses just below these reference points. Finally, Thomas (1989) tested the U.S. financial reports for rounding relative to earnings per share (EPS). For positive earnings firms, he discovered inordinately high frequencies of EPS numbers reported in multiples of $\$ .05$ and $\$ .10$, while nines in the right-most EPS digit were reported significantly less often than expected. This indicated that EPS numbers were often manipulated upward to round numbers. However, for the negative earnings firms, there was no evidence that companies tried to avoid reporting losses per share as round numbers (i.e., no evidence of manipulation or rounding of EPS). 
Niskanen and Keloharju (2000) tested for CEM in a sample of publicly traded Finnish firms with positive income for the period 1953-1997. They noted that Finnish companies differ from the New Zealand (Carslaw, 1988) or U.S. (Thomas, 1989) firms because Finnish companies normally manage earnings downward to minimize corporate income taxes paid. The researchers wanted to determine if Finnish firms would also boost earnings in order to reach user reference points. Interestingly, they found evidence of extensive manipulation as Finnish firms did not limit the upward rounding of the second earnings digit from eights and nines to zeroes, but instead rounded up from sixes and sevens to zeroes and ones. Thus, Niskanen and Keloharju (2000, p. 448) concluded that for Finnish firms "the enhancement of the first digit is not purely cosmetic," and it was likely made possible due to greater laxity in accounting rules in Finland compared to either New Zealand or the U.S.

Van Caneghem (2002) replicated the earlier CEM studies, but did so in the U.K. for listed firms with positive income in 1998. In regard to pre-tax income, the U.K. companies reported an abnormally low rate of nines in the second digit of income, while zeroes appeared significantly more often than expected. All other numbers (one through eight) occurred in the second position at their expected rates. This demonstrated the classic pattern of CEM suggesting that when the second digit of earnings was relatively high, it frequently was manipulated upward just enough to cross the threshold, thereby increasing the first digit by one. Van Caneghem (2002) also added to the literature on CEM by demonstrating that managers used discretionary accruals to achieve the earnings boosts needed to reach the user reference points.

A comprehensive study by Kinnunen and Koskela (2003) tested for CEM in 18 countries for the period 1995-1999 and found that, with few exceptions, earnings management to reach user reference points was a worldwide phenomenon. The countries in their sample demonstrating the most extensive CEM were Spain, Hong Kong, and Singapore. The researchers also discovered that the incidence of CEM varied among countries based on several factors. For example, the rate of CEM was positively related to the importance of management bonus schemes in a country but inversely associated with the amount spent on auditing and the rigidity of accounting rules within a country.

Van Caneghem (2004) focused on auditing and attempted to determine if audit quality constrains the practice of CEM. Audit quality was measured in two ways, first as Big 5 versus non-Big 5 auditors and second as industry specialist versus non-industry specialist auditors. Using the same U.K. data employed in his 2002 study, Van Caneghem's (2004) findings are inconsistent with the idea that high quality (i.e., Big 5) audits constrain CEM as the clients of both Big 5 and non-Big 5 audit firms engaged in noticeable CEM. However, when he split the Big 5 sample between clients of specialist Big 5 auditors versus clients of non-specialist Big 5 auditors, the findings were "weakly consistent with high quality (i.e., specialist Big 5) audits constraining [CEM] (Van Caneghem, 2004, p. 781)."

Skousen, Guan, and Wetzel (2004) tested Japanese firms for CEM in their annual net income for the period 1974-1997. In examining the distributions of the numbers zero through nine in the second digit of income, the researchers discovered that sevens, eights, and nines appeared significantly less often than expected, while zeroes and ones occurred at abnormally high rates. Thus, similar to the Finnish firms examined by Niskanen and Keloharju (2000), the upward manipulation of income to enhance the first digit by one for Japanese companies was fairly extensive. Interestingly, Skousen et al. (2004) discovered that Japanese managers did not limit key reference points to the first earnings digit as the second and third digits also appeared to be reference points for earnings rounding behavior. For example, there were significantly more zeroes and fewer nines than expected in the third position of earnings, which indicated that some firms manipulated income upward to enlarge the second digit by one.

Guan, He, and Yang (2006) tested for CEM in quarterly reporting in the U.S. for the period 1993-2003. They examined the frequencies of the numbers zero through nine in the second position of income for each of the four quarters reported during a year. For all four quarters, they found significantly fewer nines and more zeroes for firms with positive earnings and just the opposite effect for companies with negative income. Although the earnings rounding (manipulation) to achieve user reference points was significant in the fourth quarter reports, its intensity in this quarter was much less severe than in the first three quarters of the year. Since fourth quarter results are the only ones audited, Guan et al. (2006) surmised that the auditing process constrains the practice of CEM at least to some degree.

Cox, Guan, and Wendall (2006) examined the second earnings position for U.S. financial firms reporting positive income for signs of either upward or downward bias in their reporting. Although the exact time period of the sample is unknown, it appears the data were from the pre-2003 era. The researchers discovered that zeroes occurred in the second position of income inordinately more often than expected; this overabundance of zeroes was completely 
offset (explained) by an underrepresentation of sixes, sevens, eights, and nines in this position. The result of the upward rounding (manipulation) in the second position was an increase in the first digit by one. Cox et al. (2006) concluded that the rounding of earnings was strictly one way (i.e., upward) as no evidence existed of earnings being rounded down to a reference point.

Guan, Lin, and Fang (2008) examined a sample of listed firms in Taiwan for CEM in the period 1981-2005. Like Skousen et al.'s (2004) results for Japanese companies, Guan et al. (2008) found evidence that Taiwanese firms not only rounded the second digit of income to reach user reference points in the first digit but that also the second, third, and even fourth earnings digits sometimes were used as reference points for earnings rounding.

Lin, Zhao, and Guan (2014) tested for differences in the incidence of CEM between high-tech and low-tech firms in the U.S. during the period 1950-2011. Relative to low-tech firms, high-tech companies invest more in research and development activities, and U.S. GAAP requires these costs to be expensed immediately. Compared to high-tech firms, low-tech companies spend more on plant assets, which must be capitalized and depreciated over the future. The researchers hypothesized that because of the subjectivity involved in depreciating assets, low-tech firms had more opportunity to manage earnings and engage in CEM than high-tech firms (i.e., where GAAP is more stringent about expensing research and development costs). Lin et al.'s (2014) results supported their premise. Even though both low-tech and high-tech firms engaged in significant CEM (i.e., fewer nines and more zeroes than anticipated in the second position of earnings for firms with profits and the opposite effect for companies reporting losses), the deviations from the expected frequencies were much more severe for the low-tech firms than for the high-tech companies.

Following the implementation of SOX in 2002, a number of studies tested for CEM in the U.S. to determine if SOX deterred management's propensity to engage in this biased form of reporting. All studies analyzed the frequencies of the numbers zero through nine appearing in the second position of earnings. For example, Jordan, Clark, and Pate (2008) examined a sample of listed companies for 2006 and found no evidence of CEM for firms with negative earnings. The researchers discovered some evidence of earnings rounding to enlarge the first digit by one for companies with positive income. However, when they split the sample of positive earnings firms by entity size, no signs of CEM existed for the group of larger companies. Yet, the subsample of smaller firms reported significantly fewer nines and more ones than expected in the second position, thus suggesting upward rounding to increase the first digit by one. The researchers speculated that managers of larger companies likely face greater public scrutiny than managers of smaller firms, which could have caused the former group to curtail their earnings rounding behavior after the implementation of SOX. Wilson (2012) also tested for CEM in the U.S. for one post-SOX year (2009); he found no evidence of this manipulative behavior for either positive or negative earnings firms.

Three studies (Aono \& Guan, 2008; Jordan \& Clark, 2011; Lin \& Wu, 2014) tested for CEM in samples of U.S. firms with positive income in distinct pre-and post-SOX eras. The examinations of pre-SOX samples in all three studies revealed clear evidence of earnings manipulation to increase the first digit by one (i.e., significantly less nines and more zeroes than expected in the second digital position). In contrast, the post-SOX samples consistently displayed little or no signs of manipulation in terms of earnings rounding to achieve user reference points.

\subsection{Hypotheses Development}

As noted above, significant research indicates CEM consistently occurred both in the U.S. and globally before SOX. Furthermore, several studies suggest this form of biased reporting largely disappeared in the U.S. after SOX, with the implication that SOX played a major role in its demise. Numerous countries other than the U.S. adopted SOX-like corporate governance legislation during the early-to-mid 2000s. Yet, there exists little research on the effects of this legislation on CEM outside the U.S. Only Lin and Wu (2014) examined CEM outside the U.S. before and after corporate governance legislation, and they did so for Taiwan. The researchers noted that Taiwan represents an emerging market with less stringent accounting rules and disclosure and regulatory requirements compared to a country with a developed market, such as the U.S. Their examination revealed evidence of extensive rounding to user reference points in Taiwan prior to the corporate governance legislation in that country. While the incidence of CEM decreased in Taiwan in the post-legislation period, it still existed at a noticeable level (i.e., in the second earnings digit for firms with positive income, nines occurred significantly less often than expected while zeroes appeared at an abnormally high rate). Thus, in an emerging market (Taiwan), the corporate governance legislation seems to have constrained the practice of CEM to some degree, but certainly did not eliminate it like SOX appeared to do in the U.S.

The lack of research on the effects of corporate governance legislation on CEM outside the U.S. leads to the primary research question in the current study. More specifically, is the eradication of CEM after the implementation of 
corporate governance legislation limited to the U.S., or did it also occur in other countries with developed markets? To address this question, the incidence of CEM in Canada is examined before and after its recent corporate governance legislation became effective. Although Canada did not experience egregious financial scandals on the scale of those in the U.S. in the early 2000s, Canadian legislators and stock market regulators realized that SOX-like legislation was needed since $15 \%$ of the firms listed on Canadian exchanges are cross listed on U.S. exchanges. Further, to continue attracting international investment funds and to bolster investor confidence, Canadian regulators felt such legislation was a must (Hossain, 2013).

Unlike the U.S., which has only one governmental agency regulating the financial markets (i.e., the SEC), each of Canada's ten provinces and three territories has its own regulatory agency. The first SOX-like legislation in Canada was passed in Ontario in the form of Bill 198 during the fall of 2002. Soon after, at the behest of the Ontario Securities Commission, the Canadian Securities Administrators passed a series of multilateral instruments (MIs) and national instruments (NIs) that in combination closely resemble SOX and are frequently referred to as CSOX (Chung, Farrar, Puri, \& Thorne, 2010). The primary difference between CSOX and SOX is that CSOX does not require a company to obtain a report from its external auditors on the effectiveness of the entity's internal control system while SOX does.

Although Kinnunen and Koskela (2003) examined a relatively small sample of pre-CSOX Canadian companies as part of their study of 18 countries, none of the CEM studies prior to CSOX concentrated solely on Canada. Thus, the first hypothesis in this study addresses whether CEM existed in Canada prior to CSOX and is stated as follows:

H1: Prior to CSOX, Canadian firms will report the numbers zero through nine in the second position of income at their expected rates.

Acceptance of this hypothesis would suggest pre-CSOX earnings were not manipulated upward to achieve user reference points in the first digit. However, rejection of the hypothesis would occur and CEM would be indicated if high numbers appear in the second position of earnings significantly less often than expected, while low numbers occur at abnormally high rates.

The second hypothesis relates to the primary focus of the study; it addresses the important question of whether CEM exists in Canada in the post-CSOX era and is stated as follows:

H2: Subsequent to CSOX, Canadian firms will report the numbers zero through nine in the second position of income at their expected rates.

Acceptance of this hypothesis would indicate no CEM exists in the post-CSOX era. Rejection of $\mathrm{H} 2$ and evidence of CEM's existence after CSOX would occur if significantly less high digits and more low digits than anticipated appear in the second position of income. The combination of rejecting $\mathrm{H} 1$ and accepting $\mathrm{H} 2$ would provide anecdotal evidence that CSOX played a key role in eliminating CEM in Canada.

\section{Methodology and Data}

The method used to test for CEM in the pre- and post-CSOX periods is similar to the technique employed in prior CEM studies. In particular, digital distributions of the numbers zero through nine in the second position of income from continuing operations are evaluated to determine whether earnings are rounded up to boost the first digit by one. Only companies with positive income are examined as prior research (e.g., Thomas, 1989) shows CEM is more likely to occur in firms reporting profits than in those reporting losses.

The credibility of this study's results relies on comparing the actual rates at which the numbers zero through nine appear in the second position of income to their appropriate expected rates. Benford (1938) observed that the digits one through nine do not appear in the first (left-most) position of naturally occurring data at proportional rates (i.e., one-ninth of the time). Likewise, the digits zero through nine do not occur in the second position at proportional rates (i.e., one-tenth of the time). Rather, low digits appear in the initial two left-hand positions of naturally occurring data more frequently than high digits. Benford (1938) developed mathematical theorems to determine the expected distributions of digits occurring in each position of large numbers and then tested his expected frequencies against the actual rates of digits appearing in 20229 observations from various data sets (e.g., drainage areas of rivers, mortality rates, population statistics, etc.); he found that his rates accurately reflected the frequencies occurring in practice. Commonly referred to as Benford's Law, Table 1 presents the expected frequencies of digits appearing in the first two positions of naturally occurring data (i.e., not manipulated by man). 
Table 1. Benford's expected digital distributions

\begin{tabular}{lll}
\hline & \multicolumn{2}{l}{ Position of digit in number } \\
Digit & First & Second \\
\hline 0 & $30.10 \%$ & $11.97 \%$ \\
1 & 17.61 & 11.39 \\
2 & 12.49 & 10.88 \\
3 & 9.69 & 10.03 \\
4 & 7.92 & 9.67 \\
5 & 6.70 & 9.34 \\
6 & 5.80 & 9.04 \\
7 & 5.12 & 8.76 \\
8 & 4.58 & 8.50 \\
9 & & \\
\hline
\end{tabular}

Source: Nigrini and Mittermaier (1997)

As an example, Table 1 shows that threes should appear in the first (left-most) digital position of unmanipulated data $12.49 \%$ of the time, while sevens possess a $5.80 \%$ probability of appearing in the first position. Threes should occur in the second-from-the-left digital position $10.43 \%$ of the time, while sevens have a $9.04 \%$ chance of appearing in the second position. The numbers zero through nine should appear in the third, fourth, fifth, etc. digital positions at approximately proportional rates.

Numerous studies demonstrate that Benford's Law, along with the digital analysis it allows, represents a viable method of detecting manipulation of financial data (e.g., Coderre \& Warner, 1999; Hill, 1988; Lehman, Watson, \& Jones, 2007; Nigrini, 1999; Nigrini \& Mittermaier, 1997). Rodriguez (2004) shows that Benford's expected frequencies are particularly well suited to numbers drawn from populations with lognormal distributions that are characterized by relatively large variances. He further demonstrates that earnings possess these traits and concludes that Benford's Law represents a useful tool for evaluating the manipulation of net income. All prior studies employed Benford's rates in testing for CEM; thus, they are considered appropriate for the current study as well.

The difference between the observed and expected rates for each of the numbers zero through nine occurring in the second position of income is evaluated using a two-tailed proportions test and its resulting Z statistic. A .05 alpha level is used for determining statistical significance rather than a less stringent level (i.e., .10) to minimize the probability that differences between the frequencies are judged to be the result of manipulation when in fact they occur randomly.

The data for the pre- and post-CSOX samples are obtained for all Canadian companies with positive income in the Fundamentals Annual files reported on the COMPUSTAT database for the periods 1990-1999 and 2003-2012. To ensure the results are not influenced by any rounding of earnings that might have occurred by COMPUSTAT in reporting the data, only company-years with at least three digits shown in income are included in the samples. As noted previously, the first major installment of CSOX legislation (i.e., Ontario Bill 198) became law in the fall of 2002; thus, the period 2003-2012 represents a clear post-CSOX era. The years 1990-1999 are chosen for the pre-CSOX period because this embodies an era of time before any hints of trouble from the major financial scandals in the U.S. became known in 2000 and 2001. Once the scope of these financial frauds was known, it was obvious that legislation to prevent such frauds in the future would soon be enacted in the U.S., with Canada's lawmakers keeping a close eye on their neighbors to the south. Thus, results for the period 2001-2002 would likely have been affected by significant noise, and these years are accordingly excluded from the pre-CSOX sample.

\section{Results}

Table 2 provides descriptive statistics for total assets, sales, and income from continuing operations for the pre- and post-CSOX samples. Notice that the financial traits of the companies are fairly similar between the two periods. For example, the median sales revenue of \$155.91 million for the 2003-2012 era is only slightly larger than the median sales revenue (\$147.81 million) for the 1990-1999 period. 
Table 2. Descriptive statistics for pre- and post-CSOX samples

\begin{tabular}{|c|c|c|c|c|}
\hline Financial Measure & Mean & Median & \multicolumn{2}{|c|}{$25^{\text {th }}$ percentile $75^{\text {th }}$ percentile } \\
\hline 1990-1999 $(\mathrm{N}=5091):$ & & \multicolumn{3}{|c|}{ (in millions of dollars) } \\
\hline Total assets & 3581.10 & 195.83 & 62.84 & 788.39 \\
\hline Sales revenue & 945.47 & 147.81 & 41.20 & 561.14 \\
\hline Income cont. operations & 54.27 & 8.21 & 2.87 & 30.01 \\
\hline \multicolumn{5}{|l|}{ 2003-2012 (N=6283): } \\
\hline Total assets & 7618.84 & 256.21 & 70.68 & 1218.21 \\
\hline Sales revenue & 1556.56 & 155.91 & 38.55 & 696.85 \\
\hline Income cont. operations & 141.34 & 14.57 & 3.83 & 60.23 \\
\hline
\end{tabular}

Table 2 shows that the sample size for the post-CSOX era of 6283 firm-years exceeds the sample size for the pre-CSOX period of 5091 company-years. This difference likely occurs due to two factors. First, there obviously would be some new companies in the later period that simply did not exist in the earlier period. Second, it appears that in general the companies were somewhat more profitable in the post-CSOX period (i.e., median income of $\$ 14.57$ million) relative to the pre-CSOX era (i.e., median income of $\$ 8.21$ million). Based on these statistics, it can be implied that relative to the post-CSOX firms, a larger portion of the pre-CSOX companies would have had negative income and thus are excluded from that sample. Regardless, the samples for both periods are sufficiently large enough for statistical testing and are representative of the firms existing during the respective eras.

Panels A and B of Table 3 provide the digital distributions used for determining the existence of CEM in the pre- and post-CSOX periods, respectively. For the 1990-1999 period, Panel A presents the actual counts and rates at which each of the numbers zero through nine appear in the second position of income. As an example, zeroes occur in the second position 718 times, which represents $14.10 \%$ of the 5091 total firm-years for the pre-CSOX period. Panel A also provides Benford's expected frequencies at which each of the numbers zero through nine should appear in the second position of unmanipulated data. For example, the anticipated rate of zeroes in the second position is $11.97 \%$. Finally, Panel A presents the $\mathrm{Z}$ statistic and $\mathrm{p}$-value for a proportions test comparing the actual and expected frequencies for each of the numbers zero through nine occurring in the second position. Continuing with the analysis of zeroes, Panel A indicates that the difference between the actual and expected rates for the pre-CSOX era results in a $\mathrm{Z}$ statistic of 4.67 with a p-value of .00 .

Table 3. Distributions of numbers in second digital position of income

Digit appearing in the second earnings position

Panel A - pre-CSOX (1990-1999), N = 5091

$\begin{array}{lllllllllll}\text { Second earnings digit } & 0 & 1 & 2 & 3 & 4 & 5 & 6 & 7 & 8 & 9 \\ \text { Actual count (n) } & 718 & 600 & 570 & 511 & 469 & 520 & 471 & 460 & 406 & 366 \\ \text { Actual frequency (\%) } & 14.10 & 11.79 & 11.20 & 10.04 & 9.21 & 10.21 & 9.25 & 9.04 & 7.97 & 7.19 \\ \text { Expected frequency (\%) } & 11.97 & 11.39 & 10.88 & 10.43 & 10.03 & 9.67 & 9.34 & 9.04 & 8.76 & 8.50 \\ \text { Z statistic } & 4.67 & .87 & .70 & -.89 & -1.92 & 1.29 & -.19 & .01 & -1.96 & -3.33 \\ \text { p-value } & .00^{*} & .39 & .48 & .37 & .06 & .20 & .85 & .99 & .05^{* *} & .00^{*}\end{array}$

Panel B - post-CSOX (2003-2012), N = 6283

\begin{tabular}{lllllllllll} 
Second earnings digit & 0 & 1 & 2 & 3 & 4 & 5 & 6 & 7 & 8 & 9 \\
Actual count (n) & 773 & 714 & 658 & 648 & 640 & 639 & 567 & 562 & 530 & 552 \\
Actual frequency (\%) & 12.30 & 11.36 & 10.47 & 10.31 & 10.19 & 10.17 & 9.02 & 8.94 & 8.44 & 8.79 \\
Expected frequency (\%) & 11.97 & 11.39 & 10.88 & 10.43 & 10.03 & 9.67 & 9.34 & 9.04 & 8.76 & 8.50 \\
Z statistic & .79 & -.05 & -1.02 & -.28 & .39 & 1.32 & -.84 & -.24 & -.89 & .79 \\
p-value & .43 & .96 & .31 & .78 & .70 & .19 & .40 & .81 & .38 & .43 \\
\hline
\end{tabular}

$*, * *$ Difference between the actual and expected rates is significant at .01 or .05 level, respectively. 
Panel A for the pre-CSOX period depicts a typical pattern suggesting the presence of CEM. More specifically, two high numbers (eights and nines) appear in the second position of earnings significantly less often than expected, while zeros occur at an abnormally high rate. All other numbers (one through seven) appear in the second position at about their expected rates. Thus, H1 must be rejected as the evidence in Panel A indicates that when the second digit of unmanipulated income was relatively high, management in the pre-CSOX period often boosted earnings just across the threshold, thereby increasing the left-most digit by one.

For the post-CSOX period, however, Panel B reveals no evidence of earnings rounding (manipulation) targeting user reference points. That is, the actual rates of all numbers (zero through nine) occurring in the second position of income conform approximately to their expected frequencies; H2 must therefore be accepted. The presence of CEM in the pre-CSOX era coupled with its absence in the post-CSOX period suggests that, similar to SOX in the U.S., CSOX seems to have contributed to the elimination of this form of biased reporting in Canada.

\section{Discussion and Conclusion}

Significant research (e.g., Carslaw, 1988; Kinnunen \& Koskela, 2003; Skousen et al., 2004; Thomas, 1989) shows that earnings manipulation to achieve user reference points in the form of CEM was frequently practiced by companies in several nations prior to the enactment of corporate governance legislation in many of these same countries in the early-to-mid 2000s. Subsequently, a number of studies (Aono \& Guan, 2008; Jordan \& Clark, 2011; Lin \& Wu, 2014) examined CEM in the U.S. for pre- and post-SOX periods and found strong evidence of this biased reporting prior to SOX; however, little or no indication of this manipulation was evident after SOX. These results led to the conclusion that SOX was a major factor contributing to the demise of CEM in the U.S.

As there is a scarcity of research examining the effects of corporate governance legislation on CEM outside the U.S., the current study tests for CEM in Canada before and after implementation of that country's corporate governance legislation (referred to as CSOX). CSOX closely resembles SOX and was implemented not long after the U.S. legislation. Results of the present study suggest that prior to CSOX, companies frequently rounded up (manipulated) income in terms of classic CEM, where the first earnings digit increases by one. Subsequent to CSOX, no evidence of this manipulative behavior is observed. Thus, much like SOX in the U.S., CSOX appears to have contributed heavily to the eradication of CEM in Canada. While this result is intuitive considering the similarities of the U.S. and Canadian markets and accounting systems, it was not necessarily a given as, outside the U.S., the only other study (i.e., Lin \& Wu, 2014) examining CEM before and after corporate governance legislation found that the legislation did not eliminate this form of biased reporting in Taiwan.

As indicated in the introduction, several studies suggest that accrual-based earnings management declined precipitously in the U.S. subsequent to and as a result of SOX (e.g., Bartov \& Cohen, 2009; Cohen et al., 2008; Ibrahim et al., 2011; Kalelkar \& Nwaeze, 2011). Thus, since managers use discretionary accruals to accomplish the boosts in income needed to achieve CEM (see Van Caneghem, 2002), it stands to reason that CEM would have declined in the post-SOX era as well. However, another line of research (e.g., Gavious \& Rosenboim, 2013; Grasso, Tilley, \& White, 2009) indicates that the recent decline of earnings management in the U.S. is not attributable to SOX but rather to changes in managers' attitudes about biased reporting caused by the egregious accounting scandals that occurred in the U.S. just prior to SOX. The results of the current study in Canada shed some light on this debate.

As noted previously, the financial accounting and reporting systems in the U.S. and Canada are comparable in many ways, including the similarities between SOX and CSOX. Yet, the recent accounting environments in Canada and the U.S. differ in one crucial aspect. Canada did not experience major accounting scandals prior to CSOX like those that occurred in the U.S. in the run up to SOX (e.g., Enron, WorldCom, etc.). Hence, if the accounting scandals were the primary reason for the downturn in earnings management in the U.S., then no similar decline in earnings management should have occurred in Canada. The fact that CEM seems to have disappeared in Canada after CSOX, despite the absence of egregious accounting scandals in that country, strongly suggests the increased earnings quality observed in the U.S. in recent years was caused more by SOX than by the major financial reporting scandals that occurred there.

Like any research, the current study has some limitations that constrain the generalizability of its results. For example, since the study concentrates solely on Canada, its results do not suggest CEM has been eliminated worldwide. In addition, the current research examines CEM only for companies with positive income; thus, there exists a possibility that Canadian companies with negative earnings continue to practice CEM by avoiding reporting losses in round numbers. Also, even though Lin et al. (2014) indicated that the incidence of CEM differed between high-tech and low-tech companies in the U.S. in the pre-SOX era, no industry-specific analysis is conducted in the current study; thus, it is feasible CEM is still practiced within certain industries in Canada. The present study tests for 
upward bias in the second earnings digit to increase the first digit by one, but does not examine digital frequencies to the right of the second position. However, prior research showed that firms in Japan (Skousen et al., 2004) and Taiwan (Guan et al., 2006) did not limit their upward rounding to key reference points in the first digit as earnings digits in the second, third and even fourth positions appeared to be used as reference points for income manipulation. Did Canadian companies practice this extended form of CEM in the pre-CSOX period and, if so, does it still occur? Finally, the present study made no attempt to segregate the samples according to audit quality. Therefore, a possibility exists that CEM may still be practiced in Canada by clients of non-industry specialist auditors (e.g., see Van Caneghem, 2004). Future research would be useful in understanding these issues more fully.

\section{References}

Aono, J. \& Guan, L. (2008). The impact of Sarbanes-Oxley Act on cosmetic earnings management. Research in Accounting Regulation, 20, 205-215. http://dx.doi.org/10.1016/S1052-0457(07)00212-3

Bartov, E. \& Cohen, D. (2009). The "numbers game" in the pre- and post-Sarbanes-Oxley eras. Journal of Accounting, Auditing \& Finance, 24, 505-534. http://dx.doi.org/10.117710148558X0902400401

Benford, F. (1938). The law of anomalous numbers. Proceedings of the American Philosophical Society, 78, 551-572.

Carslaw, C. (1988). Anomalies in income numbers: Evidence of goal oriented behavior. The Accounting Review, 63, 321-327.

Chung, J., Farrar, J., Puri, P., \& Thorne, L. (2010). Auditor liability to third parties after Sarbanes-Oxley: An international comparison of regulatory and legal reforms. Journal of International Accounting, Auditing and Taxation, 19, 66-78. http://dx.doi.org/10.1016/j.intaccaudtax.2009.12.005

Coderre, D. \& Warner, P. (1999). Computer assisted techniques for fraud detection. The CPA Journal, 69(8), 57-59.

Cohen, D., Dey, A., \& Lys, T. (2008). Real and accrual-based earnings management in the pre- and post-Sarbanes-Oxley periods. The Accounting Review, 83, 757-787. http://dx.doi.org/10.2308/accr.2008.83.3.757

Cox, S., Guan, L., \& Wendall, J. (2006). Biased rounding in the reported earnings of financial firms. Bank Accounting \& Finance, 19(5), 29-32.

Gavious, I. \& Rosenboim, M. (2013). The disciplining role of the market versus government regulation: The case of Sarbanes-Oxley and the earnings quality of M\&A targets. American Law \& Economics, 15, 300-332. http://dx.doi.org/10.1093/aler/ahs032

Grasso, L., Tilley, P., \& White, A. (2009). The ethics of earnings management perceptions after Sarbanes-Oxley. Management Accounting Quarterly, 11(1), 45-69.

Guan, L., He, D., \& Yang, D. (2006). Auditing, integral approach to quarterly reporting, and cosmetic earnings management. Managerial Auditing Journal, 21, 569-581. http://dx.doi.org/10.1108/02686900610674861

Guan, L., Lin, F., \& Fang, W. (2008). Goal-oriented management behavior: Evidence from Taiwanese firms. Emerging Markets Finance \& Trade, 44(4), 19-32. http://dx.doi.org/10.2753/REE1540-496X440402

Healy, P. \& Wahlen, J. (1999). A review of the earnings management literature and its implications for standard setting. Accounting Horizons, 13, 365-383. http://dx.doi.org/10.2308/acch.1999.13.4.365

Hill, A. (1988). Random-number guessing and the first digit phenomenon. Psychological Reports. 62, 967-971. http://dx.doi.org/10.2466/pr0.1988.62.3.967

Hossain, A. (2013). Impact of Canadian SOX on Canadian acquisitions. Journal of Accounting and Finance, 13(5), $11-25$.

Ibrahim, S., Xu, L., \& Rogers, G. (2011). Real and accrual-based earnings management and its legal consequences: Evidence from seasonal equity offerings. Accounting Research Journal, 24, 50-78. http://dx.doi.org/10.1108/10309611111148779

Jackson, S. \& Pitman, M. (2001). Auditors and earnings management. The CPA Journal, 71(7), 39-44.

Jordan, C. \& Clark, S. (2011). Detecting cosmetic earnings management using Benford's Law. The CPA Journal, 81(2), 32-37. 
Jordan, C., Clark, S., \& Pate, G. (2008). Earnings manipulation to achieve cognitive reference points in income. Academy of Accounting \& Financial Studies Journal, 12(3), 97-112.

Kalelkar, R. \& Nwaeze, E. (2011). Sarbanes-Oxley Act and the quality of earnings and accruals: Market-based evidence. Journal of Accounting and Public Policy, 30, 275-294. http://dx.doi.org/10.1016/j.jaccpubpol.2011.02.004

Ketz, J. (1999). Update: How goes the SEC's war against earnings management? Journal of Corporate Accounting and $\quad$ Finance, 10(3), 41-52. http://dx.doi.org/10.1002/(SICI)1097-0053(199921)10:3<41::AID-JCAF4>3.0.CO;2-H

Kinnunen, J. \& Koskela, M. (2003). Who is Miss World in cosmetic earnings management? A cross-national comparison of small upward rounding of net income numbers among eighteen countries. Journal of International Accounting Research, 2, 39-68. http://dx.doi.org/10.2308/jiar.2003.2.1.39

Lehman, M., Watson, M., \& Jones, T. (2007). Flexing your financial sleuth power. Journal of Accountancy, 203(6) 50-54.

Lin, F. \& Wu, S. (2014). Comparison of cosmetic earnings management for the developed markets and emerging markets: Some empirical evidence from the United States and Taiwan. Economic Modelling, 36, 466-473. http://dx.doi.org/10.1016/j.econmod.2013.10.002

Lin, F. Zhao, L., \& Guan, L. (2014). Window dressing in reported earnings: A comparison of high-tech and low-tech companies. Emerging Markets Finance \& Trade, 50, 254-264. http://dx.doi.org/10.2753/REE1540-496X5001S116

Nigrini, M. (1999). I've got your number. Journal of Accountancy, 187(5), 79-83.

Nigrini, M. \& Mittermaier, L. (1997). The use of Benford's Law as an aid in analytical procedures. Auditing: A Journal of Practice \& Theory, 16(2), 52-67.

Niskanen, J. \& Keloharju, M. (2000). Earnings cosmetics in a tax-driven accounting environment: Evidence from Finnish public firms. European Accounting Review, 9, 443-452. http://dx.doi.org/10.1080/09638180020017159

Ontario Legislature. (2002). Ontario Bill 198: Act to Implement Budget Measures and Other Initiatives of the Government.

Rodriguez, R. (2004). Reducing false alarms in the detection of human influence on data. Journal of Accounting, Auditing \& Finance, 19, 141-158. http://dx.doi.org/10.1177/0148558X0401900202

Skousen, C., Guan, L., \& Wetzel, T. (2004). Anomalies and unusual patterns in reported earnings: Japanese managers round earnings. Journal of International Financial Management \& Accounting, 15, 212-234. http://dx.doi.org/10.1111/j.1467-646X.2004.00108.x

Thomas, J. (1989). Unusual patterns in reported earnings. The Accounting Review, 64, 773-787.

Van Caneghem, T. (2002). Earnings management induced by cognitive reference points. British Accounting Review, 34, 167-178. http://dx.doi.org/10.1006/bare.2002.0190

Van Caneghem, T. (2004). The impact of audit quality on earnings rounding-up behavior: Some UK evidence. European Accounting Review, 13, 771-786. http://dx.doi.org/10.1080/0963818042000216866

Wilson, T. (2012). Further evidence on the extent of cosmetic earnings management by U.S. firms. Academy of Accounting and Financial Studies Journal, 16(3), 57-64. 